\title{
Primary oxalosis of the heart: a cause of heart block
}

\author{
D. J. Coltart ${ }^{1}$ and R. E. B. Hudson \\ From the Department of Cardiology, St. Bartholomew's Hospital, London E.C.I, \\ and the Pathology Department, National Heart Hospital and Institute \\ of Cardiology, London W.I
}

$A$ review of the cardiac manifestations of primary oxalosis is presented, together with an illustrative example in a girl who died at I8 years. Arrhythmias, particularly heart block, can present as an acute medical emergency in this condition; in the patient described, histological study of the cardiac conducting system after death showed bilateral bundle-branch fibrosis, associated with calcium oxalate deposition, as the cause of the heart block. Though no definitive treatment of the disease is yet available, current regimens may prolong survival when cardiac manifestations become prominent.

Primary oxalosis is a rare hereditary inborn error of metabolism, characterized clinically by nephrolithiasis and nephrocalcinosis in childhood, leading to progressive renal failure and death from uraemia. In the most progressive form of the disease there are extrarenal deposits of calcium oxalate in many tissues (oxalosis), including the bone marrow, heart, and urogenital system. Oxalic acid is normally derived from the amino acid glycine via glyoxylic acid, which mostly metabolizes to formate and carbon dioxide. In primary oxalosis there may be deficiency of an enzyme, possibly glycine- $\alpha$-ketoglutonate transaminase, permitting excessive accumulation of glyoxalic acid in the tissues, where it deposits as calcium oxalate crystals (Weinhouse, 1955) which do not provoke inflammation. The crystals do not stain with haematoxylin, but they do with von Kossa's stain for calcium, and they are easily detected by polarized light as rosettes with radial striation. The urinary daily excretion of calcium oxalate is raised constantly above the maximum normal of $40 \mathrm{mg}$. (Archer et al., 1957).

It is not the purpose of the review to describe detailed metabolic studies of our patient; this was done by Crawhall and Watts (1962); we are reporting the cardiological manifestations and complications of the disease, which can present, as in our patient,

1 Address for Reprints: Dr. D. J. Coltart, Department of Cardiology, St. Bartholomew's Hospital, London E.C.r. as an acute emergency which may take the physician unawares.

\section{Case report}

The patient, a girl of 18 years, was well until the age of 5 years, when she had frequent episodes of vomiting and renal colic and was found to have multiple renal calculi; there was no relevant family history. Five years later she underwent a left nephrolithotomy, but subsequently had many attacks of renal colic, usually on the left side, sometimes on the right, associated with the passing of a calculus. At the age of 13 years she began long-term prophylaxis for urinary tract infection and at 14 she underwent the detailed metabolic study reported by Crawhall and Watts (1962). At I6 years routine abdominal $x$-ray showed several calculi impacted at the lower end of the right ureter; these were subsequently passed spontaneously. In December 1969, when she was 18 , she was admitted to hospital with right loin pain and anuria. An emergency bilateral ureterolithotomy showed multiple stones in both ureters; these were removed, but postoperatively the patient became uraemic for the first time, with blood urea of $185 \mathrm{mg}$./100 ml., serum potassium $4.5 \mathrm{mEq} / \mathrm{l}$., and urine output of 1650 ml./24 hours. On protein restriction the blood urea level fell with a good urine output, but on the sixteenth postoperative day she became progressively oliguric and another stone was shown at the lower end of the right ureter; this was removed through the previous incision. After this the urine output was approximately $1500 \mathrm{ml} . / 24$ hours, blood urea $150 \mathrm{mg}$./100 ml., and serum potassium $4 \cdot 1 \mathrm{mEq} / \mathrm{l}$., but during the next week she became progressively more uraemic and 
oliguric. On the seventh day after the previous intervention a bilateral retrograde ureterogram excluded the possibility of a further calculus, and an acute renal failure regimen was instituted. A week later electrocardiography, which was previously normal, showed 2 : I atrioventricular block. The next day, when the patient's blood urea was $290 \mathrm{mg}$. $/ 100 \mathrm{ml}$. and serum potassium $4.3 \mathrm{mEq} / \mathrm{l}$., she had a single epileptiform fit with unrecordable blood pressure and slow pulse; the electrocardiogram (Fig. I) now showed complete heart block. A No. 5 bipolar pacemaking catheter was inserted via the right external jugular vein into the right ventricle and pacemaking was begun at a 2-volt threshold; it failed intermittently. Later that day, after a brief period of peritoneal dialysis, a Scribner arterial venous shunt was inserted in the left arm and haemodialysis instituted. During the next week her condition improved, but early in January 1970 she had a syncopal attack from pacing failure without increase in the threshold voltage. Her feet became cold and gangrenous; this was associated with bilateral absence of the femoral pulses, thought to be due either to emboli or to calcification in the arteries. Dialysis was discontinued and the patient died in terminal renal failure. Throughout the period of haemodialysis there was electrical instability of the pacemaker with no change in threshold voltage.

At necropsy the heart was first sampled and then submitted to one of us (R.H.) for special study of the conducting system. The portion received weighed $290 \mathrm{~g}$., the apical third having been removed previously. There was no macroscopical lesion of the chambers, valves, or coronary arteries, but microscopically there was widespread deposition of calcium oxalate crystals in the myocardial cells, interstitial tissue, and in the walls of coronary arteries and veins (Fig. 2 and 3 ). This was accompanied by patchy replacement fibrosis in which ordinary haematoxophilic calcification was also proceeding (Fig. 4). The oxalate crystals were easily demonstrable in polarized light, and occurred singly and in groups. They reacted with Von Kossa's stain, as did the ordinary calcification. They dissolved in weak hydrochloric acid and the solution decolorized potassium permanganate solution. Deposition was most abundant in the left ventricle and it caused some focal disruption of the tissue at the site, especially well seen in the medial plain muscle of coronary arteries. The larger single crystals were seen under high power to contain one or two reddish dots in polarized light. Virtually no crystals were detected in the valve cusp, pulmonary trunk, or aorta.

Sinuatrial node No crystals were detected in the nodal myocardium, but one section showed deposition in the wall of the node artery (Fig. 3B).

Atrioventricular system (Fig. 4) The relevant block of tissue, $3 \mathrm{~cm}$. long, was cut serially into sections, each $6 \mu \mathrm{m}$. thick; every 3oth section was mounted and stained, yielding I30 sections, approximately 4 per $\mathrm{mm}$.
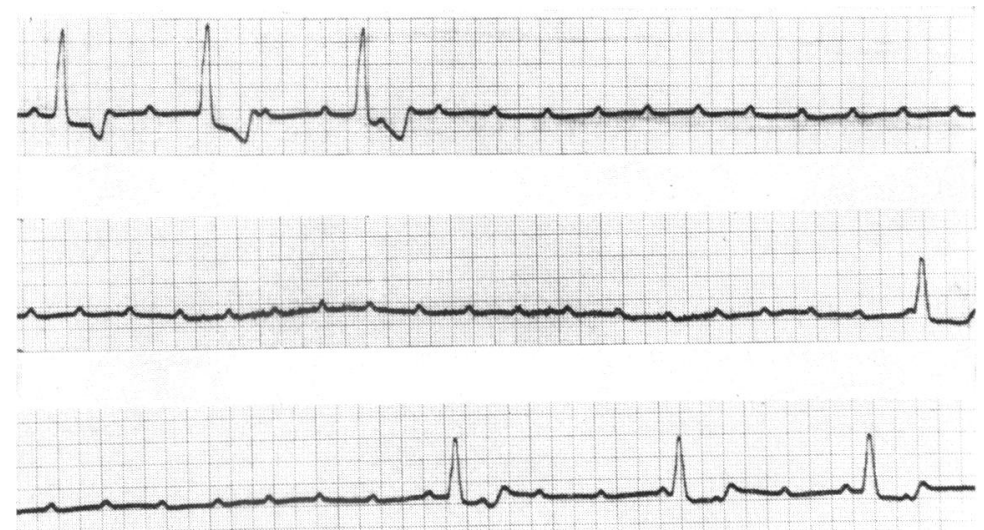

II

FIG. I Electrocardiogram showing complete

heart block with prolonged ventricular

asystole.

The AV node and bundle of His (Fig. 5A and 5B) were normal but showed scanty crystals in the myocardium and related arteries (Fig. $5 \mathrm{C}$ ).

The left fascicles were poorly connected to the bundle of His, being interrupted in places; numerous crystals were present in the fascicles,

FIG. 2 Primary oxalosis of the left ventricle photographed with partly polarized light.

(A) Area of replacement fibrosis with scattered oxalate crystals, occurring singly and in masses, as bright points of light. $(H$. and $E$. $\times$ 38.) (B) $A$ large calcium oxalate crystal in a myocardial cell. Nearby are foci of fibrosis; another crystal is present at top right. (H. and E. $\times$ 410.)
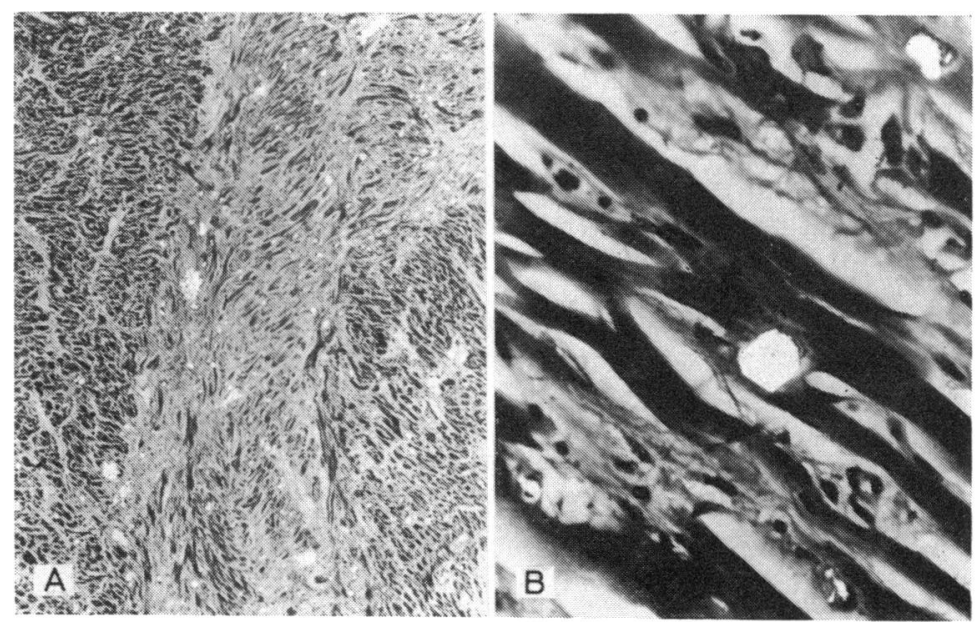


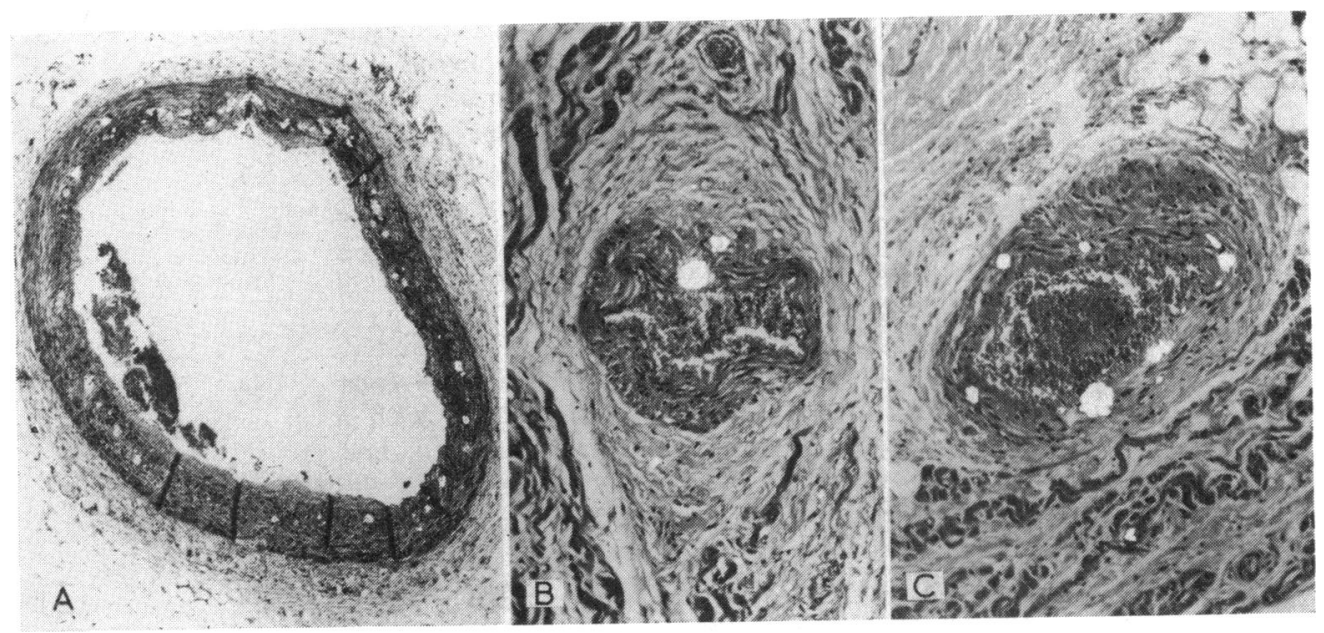

FIG. 3 Coronary arteries in primary oxalosis, showing crystal deposition. Photographed with partly polarized light. $(A)$ Right main coronary artery. There are numerous calcium oxalate crystals scattered in the media. $(H$. and $E . \times 38).(B)$ Sinuatrial node artery showing mural crystals. (H. and E. $\times I 20$.) (C) Atrioventricular node artery showing mural crystals. $(H$. and E. $\times 120$.

FIG. 4 Left ventricle in primary oxalosis, photographed with partly polarized light to show the brightly anisotropic calcium oxalate crystals mingled with ordinary haematoxophilic calcification (dark areas) in an area of replacement fibrosis. (H. and E. $\times 120$.

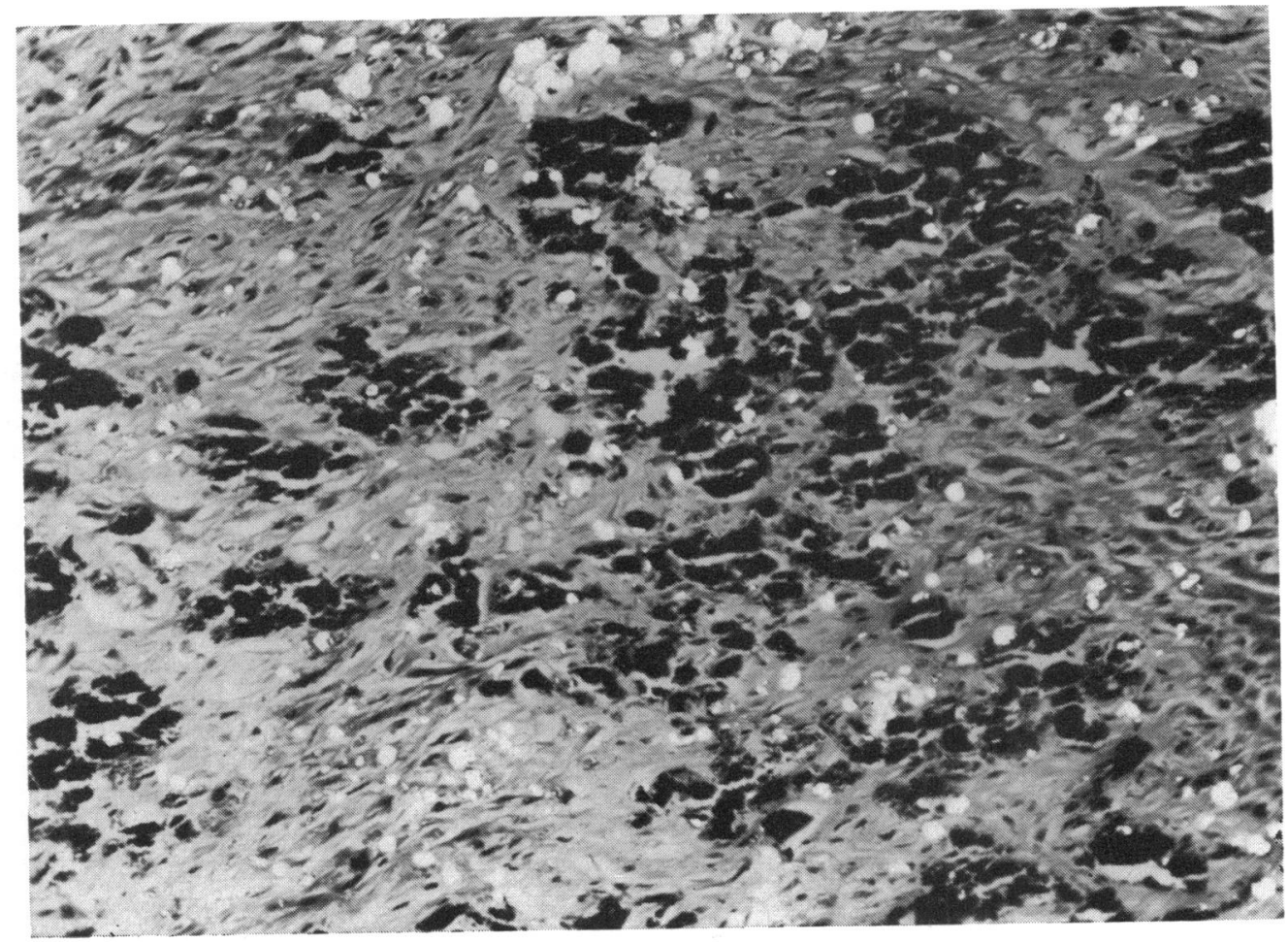


which more distally entered a zone of subendocardial fibrosis (Fig. $5 \mathrm{E}$ ). The right branch was large and well defined at its origin (Fig. $5 \mathrm{C}$ ), but more distally it showed numerous crystals and severe replacement fibrosis (Fig. 5D). The damage to the left and right branches was thought sufficient to account for the heart block detected in life.

\section{Discussion}

The course of the disease in our patient was characteristic of primary oxalosis. The onset of the conduction defect suggested that the conducting system was involved by crystal deposition; similarly, myocardial deposition was suggested by the intermittent failure of pacemaking. Both of these lesions were confirmed at necropsy, which showed widespread crystal deposition and fibrosis in the myocardium, especially in the left ventricle, with similar lesions in both branches of the bundle of His; there was also some non-specific calcification in the areas of replacement fibrosis. Crystals were found also in the walls of coronary arteries and veins but not in the valve cusps, nerves, pulmonary trunk, or aorta. Deposition was abundant in the left ventricle but much less evident in the walls of other chambers.

Edwards (1957) reported cardiac arrhythmias in primary familial oxalosis, and Godwin et al. (1958) detected scanty oxalate crystals in the myocardium at necropsy of their patients. Scowen, Stansfeld, and Watts (1959) described the necropsy findings in one of Archer et al.'s patients who died at the age of 23 years; the kidneys were shrunken and

FIG. 5 The atrioventricular conducting system in primary oxalosis, photographed with partly polarized light, showing bilateral bundle-branch damage. All sections stained by $H$. and $E . \times 38$.

(A) Atrioventricular node, outlined by arrows; it contains a scattering of oxalate crystals, showing as bright dots, but is otherwise normal. (B) Bundle of His (upper arrows) and its left fascicles (lower arrows) showing scanty oxalate crystals. (C) Right branch near its origin, outlined by arrows; it is normal apart from a few crystals. (D) Right branch, between the arrows, showing numerous crystals and severe replacement fibrosis (compare with $C$ ). (E) Poorly-defined left fascicles (arrows) in the left ventricle traversing a zone of subendocardial fibrosis in which there are scattered crystals. gritty, with calcium oxalate crystals abundant especially in the tubules, hydronephrosis, and hypertension, with vascular changes. Crystals were found also in the myocardial cells, in interstitial tissue (sometimes with a few macrophages), in the media of coronary arteries and arterioles, in atheroma plaques, in the testes, thyroid, and bones, and in several other sites.

Stauffer (1960) described a case similar to but younger than ours; she was only 13 years old and she developed heart block, with a ventricular rate of 40 per minute, Io days before death; she also developed hyperkalaemia on the last day of life. Necropsy showed calcium oxalate crystals in the myocardial cells and interstitium. Slama, Josso, and Antoine (1960) described the cardiac manifestations of the disease, noting especially the arrhythmias.

McLaurin et al. (I96I) described a patient who had hyperoxaluria and repeated episodes of paroxysmal atrial tachycardia, thought to be caused by myocardial deposition of crystals. Enger, Serck-Hanssen, and Rokkones (1965)

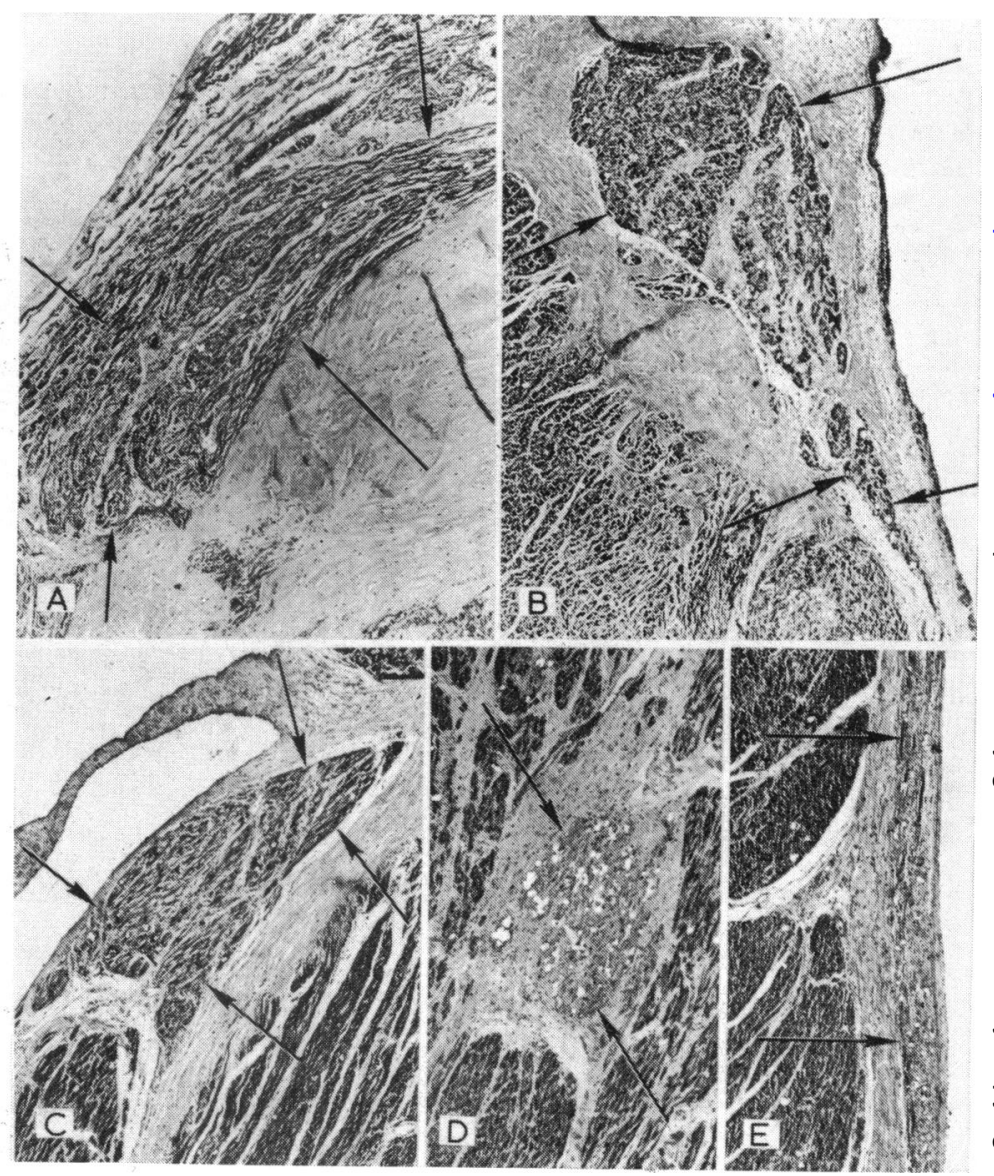


reported the presence of oxalate crystals in the bundle of His at necropsy in their patient.

Oxalosis has been described in older patients; an example in a man of 62 was the subject of a Clinicopathological Conference (196I) at the Postgraduate Medical School of London; he died of uraemia and the pericardium contained a bloodstained fibrinous deposit. The heart weighed $580 \mathrm{~g}$. (the man was $6 \mathrm{ft} .7$ in. (I9I cm.) tall). Oxalate crystals were abundant in the kidneys and to lesser degree in the heart, tongue (especially in the media of small arteries), in abdominal lymph nodes, in the gastric mucosa, in an apical lung scar, a sublingual gland, the seminal vesicles, and in the aortic media. Two similar examples in men past middle age were described by Koten et al. (1965). The first was 66 years old and presented with uraemia, calculus in the left renal pelvis, occlusion of leg arteries, and old cardiac infarction. At necropsy the heart weighed $500 \mathrm{~g}$. and the kidneys were granular; microscopy showed numerous birefringent crystals in the rosettes or sheaves in the proximal tubules in the muscle and fibrous tissue of the myocardial scar and in the arteries between the media and internal elastic lamella. The second man was 62 years old and had lassitude, proteinuria, and right renal calculus; biopsy showed glomerular and tubular crystals soluble in hydrochloric acid but not in ro per cent acetic acid. He died, and necropsy disclosed haemorrhagic pericardial effusion, pleural effusions, and crystals in the kidneys, myocardial scars (evoking giant-cell reaction), aorta, arteries, pancreas, lungs, liver, spleen, adrenals, prostate, testes, and elsewhere. In both patients there was haemosiderosis of the spleen and marrow and evidence of secondary (renal) hyperparathyroidism.

On the whole the therapy of primary oxalosis has proved unavailing. Haemodialysis can remove some of the endogenously produced oxalate and possibly slow down crystal deposition (Zarembski, Hodgkinson, and Parsons, 1966) but peritoneal dialysis does not remove oxalate as fast as it is produced (Zarembski, Rosen, and Hodgkinson, 1969). Our patient did not survive long enough to benefit from haemodialysis though transient improvement was noted. Walls, Morley, and Kerr (1969), however, reported a patient who underwent haemodialysis for I4 months and who died suddenly of cardiac arrest. At necropsy crystals and delicate fibrosis were found in the left ventricle, but scanty crystals without fibrosis were present in the right ventricle and bundle of His. Dense crystalline deposits were present in the media of the coronary arteries and in the aortic wall.

Renal transplantation, too, seems to be useless, because calcification in the transplant occurs within 3 months (Williams and Smith, 1968).

We are grateful to Dr. R. W. E. Watts and Dr. W. R. Cattell for permission to publish this case and to Dr. A. G. Stanfield for the necropsy specimen.

D.J.C. is in receipt of a grant from Imperial Industries Limited and is the Mary Schalieb Research Scholar, 1970/71, of the University of London.

\section{References}

Archer, H. E., Dormer, A. E., Scowen, E. F., and Watts, R. W. E. (1957). Primary hyperoxaluria. Lancet, 2, 320.

Clinicopathological Conference (196I). Oxalosis in an adult. Demonstrated at the Postgraduate Medical School of London. British Medical fournal, 2, 637.

Crawhall, J. C., and Watts, R. W. E. (1962). The metabolism of $\left[\mathrm{I}-{ }^{14} \mathrm{C}\right]$ glyoxylate by the liver mitochondria of patients with primary hyperoxaluria and non-hyperoxaluric subjects. Clinical Science, 23, 163.

Edwards, D. L. (1957). Idiopathic familial oxalosis. Archives of Pathology, 64, 546.

Enger, E., Serck-Hanssen, A., and Rokkones, T. (1965). Oxalosis. A case report. Acta Medica Scandinavica, 177, 409.

Godwin, J. T., Fowler, M. F., Dempsey, E. F., and Henneman, P. H. (1958). Primary hyperoxaluria and oxalosis. Report of a case and review of the literature. New England fournal of Medicine, 259, I099.

Koten, J. W., van Gastel, C., Dorhout Mees, E. J., Holleman, L. W. J., and Schuiling, R. D. (1965). Two cases of primary oxalosis. Fournal of Clinical Pathology, 18, 223.

McLaurin, A. W., Beisel, W. R., McCormick, G. J., Scalettar, R., and Herman, R. H. (196I). Primary hyperoxaluria. Annals of Internal Medicine, 55, 70.

Scowen, E. F., Stansfeld, A. G., and Watts, R. W. E. (1959). Oxalosis and primary hyperoxaluria. Fournal of Pathology and Bacteriology, 77, 195.

Slama, R., Josso, F., and Antoine, B. (I960). Manifestations myocardiques de l'oxalose. Archives des Maladies du Coeur et des Vaisseaux, 53, 917.

Stauffer, M. (1960). Oxalosis. New England Fournal of Medicine, 263, 386.

Walls, J., Morley, A. R., and Kerr, D. N. S. (1969). Primary hyperoxaluria in adult siblings: with some observations on the role of regular haemodialysis therapy. British fournal of Urology, 41, 546.

Weinhouse, S. (1955). The synthesis and degradation of glycine. In $A$ Symposium on Amino Acid Metabolism, p. 637. Ed. by W. D. McElroy and H. B. Glass. Johns Hopkins Press, Baltimore.

Williams, H. E. and Smith, L. H. (1968). Disorders of oxalate metabolism. American fournal of Medicine, 45, 715.

Zarembski, P. M., Hodgkinson, A., and Parsons, F. M. (1966). Elevation of the concentration of plasma oxalic acid in renal failure. Nature (London), 212, SII.

, Rosen, S. M., and Hodgkinson, A. (1969). Dialysis in the treatment of primary hyperoxaluria. British fournal of Urology, 41, 530 . 